Research Article

\title{
Dental Fluorosis according to Birth Cohort and Fluoride Markers in an Endemic Region of Colombia
}

\author{
Alexandra Saldarriaga $\left(\mathbb{D},{ }^{1,2}\right.$ Manuel Restrepo ${ }^{(D)},{ }^{2}$ Diego F. Rojas-Gualdrón $\mathbb{D}^{3}{ }^{3}$ \\ Thamyris de Souza Carvalho $\left(\mathbb{D},{ }^{4}\right.$ Marilia Afonso Rabelo Buzalaf $(\mathbb{D}){ }^{4}$ \\ Lourdes Santos-Pinto $\mathbb{D},^{5}$ and Fabiano Jeremias $\mathbb{D}^{1}$ \\ ${ }^{1}$ Graduate Program in Dental Science, São Paulo State University (UNESP), School of Dentistry, Araraquara, São Paulo, Brazil \\ ${ }^{2}$ School of Dentistry, CES University, Medellín, Colombia \\ ${ }^{3}$ School of Medicine, CES University, Medellin, Colombia \\ ${ }^{4}$ Department of Biological Sciences, University of São Paulo (USP), Bauru School of Dentistry, Bauru, São Paulo, Brazil \\ ${ }^{5}$ Department of Morphology and Orthodontics and Pediatric Dentistry, São Paulo State University (UNESP), School of Dentistry, \\ Araraquara, São Paulo, Brazil
}

Correspondence should be addressed to Fabiano Jeremias; f.jeremias@unesp.br

Received 26 October 2020; Revised 24 February 2021; Accepted 1 March 2021; Published 8 March 2021

Academic Editor: Marcelo H. Napimoga

Copyright (c) 2021 Alexandra Saldarriaga et al. This is an open access article distributed under the Creative Commons Attribution License, which permits unrestricted use, distribution, and reproduction in any medium, provided the original work is properly cited.

\begin{abstract}
Objectives. To analyze changes in the dental fluorosis (DF) incidence according to a birth cohort and explore current exposure to DF in a case series. Methods. Repeated cross-sectional study of two periods: 2015 and 2018. Two standardized examiners registered DF using the Thylstrup-Fejerskov index in permanent teeth of children aged 7-18 years. Period and birth cohort frequencies were estimated by a generalized linear model, binomial family, and logarithmic link function. Period estimates are presented as prevalence ratios (PR) and birth cohort estimates as cumulative incidence ratios (RR); $95 \%$ confidence intervals and $P$ values are reported. In a subsample of 37 volunteers $(12.29 \pm 2.63$ years), the fluoride $(F)$ concentration in toenails was measured using the HMDS diffusion method and an ion-specific electrode. Other samples from the local environment such as food, soil, and coal were also collected. Results. In 274 children, we found that nonsignificant increases between periods (PR $=1.17 ; 95 \%$ CI: $0.89-1.55)$ were not explained by birth cohort effects. A total of $37.8 \%$ of the subsample had a toenail F concentration $\geq 2 \mu \mathrm{g} F / \mathrm{g}$. The salty snacks and seasoning had the highest $\mathrm{F}$ concentrations among local environmental samples. Conclusion. In this population with a high DF frequency according to birth cohort and the evaluated period, the study of soil, coal, and food samples indicated a continued $\mathrm{F}$ exposure. F concentration found in the toenails shows a moderate F exposure; nearly a third of the children and adolescents exceeded the adopted threshold of $2 \mu \mathrm{g} \mathrm{F} / \mathrm{g}$. It is important to monitor and explore changes in exposure in highly affected population.
\end{abstract}

\section{Introduction}

Over the last decades, exposure to fluoride (F) has increased in fluorinated and nonfluorinated communities $[1,2]$. The critical moment for the development of dental fluorosis (DF) in primary teeth is between 6 and 9 months of age [3]. In permanent dentition, a longer period should be considered, which varies depending on the tooth type and the duration of exposure to $\mathrm{F}$ during amelogenesis $[1,4-7]$.
Children in contemporary societies may be exposed to multiple sources of $\mathrm{F}$ at different periods of their lives, and yet the most appropriate period to supply $\mathrm{F}$ maintaining a risk-benefit balance is unknown $[5,8]$.

The large window of susceptibility of DF is well known $[1,5]$. However, there is still controversy regarding the variety of F's sources and the presence of risk factors such as climate, altitude, and geographic conditions $[4,7,9]$. DF is a condition, which is more related to chronic $\mathrm{F}$ accumulation 
during the child's growth and development than with an exposure limited to specific critical periods $[4,5,10]$.

Epidemiological studies have focused mainly on its prevalence. Although some consider that a certain degree of DF is physiologic and does not harm the population $[11,12]$, the high prevalence and severity in populations with systemic fluoridation has generated concern in the scientific community. The DF frequency can vary in the same region over time, depending on the behavior of its risk and protective factors. These factors can affect the rates according to the cohort [13].

The study of the DF frequency changes can provide guidelines to analyze the balance between the etiological factors and identify if the rate variations are associated with the birth cohort. Along with the monitoring of exposure to $\mathrm{F}$ through biomarkers in endemic regions, this analysis can contribute to identifying specific population behaviors and yet unidentified sources and factors. F can be a safe and effective preventive method when adequately used, and low constant concentrations in the oral fluids may be sufficient. New studies could change paradigms regarding F's dose and risk-benefit balance and contribute to its epidemiological surveillance $[4,9,14,15]$.

The primary aim of this study was to analyze changes in the DF incidence, according to a birth cohort as a possible explanation for the increase in its prevalence in an endemic region of northern Colombia. The secondary aim was to characterize and explore the $\mathrm{F}$ exposure in a case series, using toenails as a biomarker, and to evaluate its presence in food snacks, a widely used food seasoning, and some local geological elements.

\section{Materials and Methods}

2.1. Study Design. This analytical cross-sectional study of the cohort effect analyzed the DF frequency in two time periods (2015-2018) in a children population of 8-18-year-old from a region in northern Colombia (El Cedro). We characterized the $\mathrm{F}$ concentration in toenails as an exposure biomarker in a nested case series.

This study, which was approved by the CES University's Institutional Committee of Ethics of Research in Humans (Medellin, Colombia) (Act No. 110, Code 718), is part of a macroproject aimed to analyze and characterize DF. The participant children and their parents signed an informed assent and informed consent, respectively.

The El Cedro district in northern Colombia is part of a Health Program of Cooking Salt Fluoridation (180-220 F $\mathrm{ppm})$. This endemic DF population has a mean $\mathrm{F}$ concentration of $123.6 \pm 89.4$ in salt and $0.10 \mathrm{~F} \mathrm{ppm}$ in water [16]. Its 2015 total population was 929 inhabitants (density of 6.15 inhabitants per $\mathrm{km}^{2}$ ). A first clinical evaluation was conducted in 2015, where 187 children aged $8-12$ years $(n=225)$ [16]. During a health visit in 2018, a call was made to all students over eight years old $(n=490)$, including children evaluated in 2015. Only 182 children attended. To analyze the changes in frequency, based on the cohort effect in the prevalence of the samples evaluated in 2015-2018, we included a sample of 274 children. All schoolchildren were invited to both examinations.

The inclusion criteria were children residents of El Cedro who were examined in 2015 or 2018 and had at least the maxillary and mandibular first permanent molars and permanent incisors. The exclusion criteria were the presence of syndromes associated with enamel malformations, enamel defects caused by trauma, and children wearing orthodontic appliances.

The clinical examination was performed in a dental office equipped with artificial light, a suction system, and an airwater syringe, using no. 5 mouth mirror and the WHO periodontal probe [17]. After cleaning with a professional prophylaxis and drying the teeth with gauze, two standardized examiners ( 0.89 and 0.87 to Kappa intra and interexaminer, respectively) on the Thylstrup-Fejerskov index (TFI) [18] for the DF diagnosis performed a complete examination of all permanent teeth present. The diagnosis of white spot lesions and other enamel opacities was based on the Seow criteria [19]. The examiners were the same at both timepoints.

According to the birth year, the participants were classified into cohorts (2000-2002, 2003-2005, 2006-2008, and 2009-2010). The cohort effect was quantified as positive cases in each period divided by the number of children born in the same period. The period effect was calculated as the total number of positive cases divided by the total number evaluated in 2015 and 2018. Also, variables such as age at examination and year were considered.

\subsection{Sample Collection}

2.2.1. Toenails. For the exploration, analysis, and quantification of fluorides, with the aim of achieving a sample size between 30 and 40 samples, toenails were collected from a sample of 37 children with DF diagnostic. The inclusion criteria were children residents of El Cedro, of both genders, with clinical exam, TFI score $\geq 1$, with a preference for a score TFI $>1$.

For the toenail collection, parents were instructed to allow children's toenails to grow for 15 days before cutting. They were also asked not to paint the toenails. The collected samples were stored and coded. Each toenail was washed with deionized water using an interdental brush, deionized in a water container for 10 minutes, and dried at $60 \pm 5^{\circ} \mathrm{C}$ for 12 hours. Finally, the toenails were weighted.

2.2.2. Soil and Coal. As an exploratory analysis, soil and coal samples were taken from two strategic areas of the region: one in the central part and another from a peripheral area of El Cedro. A $40 \mathrm{~cm}$ hole was made for the soil sampling, 
collecting its deepest soil and filling two $200 \mathrm{ml}$ containers. The coal sample was taken directly from the woodstove.

2.2.3. Snacks and Food Seasoning. Samples of the children's most commonly consumed snacks and from a popular food seasoning used in this region were obtained from El Cedro schools and nearby stores.

Soil, coal, and food samples were macerated, placed in Petri dishes, and weighted to obtain $0.50-0.59 \mathrm{mg}$ in $\mathrm{du}-$ plicates. The samples were kept at room temperature until they were analyzed.

2.3. Fluoride Analysis. Fluoride analysis was performed in the laboratory at the Bauru School of Dentistry, University of São Paulo, Brazil. All fluoride analysis performed on samples were made in duplicate. Each snack or food was measured twice for fluoride analysis; all the toenails samples were made in biological duplicates. All were encoded and chemically analyzed by diffusion. The toenail samples ranged from $10 \mathrm{mg}$ to $12 \mathrm{mg}$. [20].

The $\mathrm{F}$ concentration was determined after overnight hexamethyldisiloxane-facilitated diffusion [21] as modified by Whitford [7], using a model $9409 \mathrm{~F}$ electrode (Orion) and a miniature calomel reference electrode (Accumet, no. 13620-79) connected to a potentiometer (model EA-940, Orion). During diffusion (at room temperature), the solutions in the nonwettable Petri dishes (Falcon no. 1007) were gently swirled on a rotary shaker. F standards $(50.0,10.0,5.0$, $1.0,0.5$, and $0.25 \mu \mathrm{g} \mathrm{F}$ ) were prepared by serial dilution of a stock solution $0.1 \mathrm{M} \mathrm{F}$ (Orion) in triplicate and diffused in the same manner as the samples. The mean repeatability of the readings, based on duplicate samples, was $95 \%$ (it means that only data with $95 \%$ of repeatability on duplicate readings were acceptable). The standard curve had a coefficient of determination $\geq 0.98[20]$.

2.4. Statistical Analysis. The data were analyzed in the Software for Statistics and Data Science (STATA), version 16. For the descriptive analysis, we used frequencies and percentages for the categorical variables and measures of central tendency and dispersion for the quantitative variables. For the risk difference analysis, according to the birth cohort, a generalized linear model using the binomial family and logarithmic link considered the age and examination year as covariates. The results were presented as RR with $95 \%$ confidence intervals, $P$ value, and second-generation $P$ values (SGPV) [22].

All the data obtained from the direct $\mathrm{F}$ measurement were analyzed and recorded for their description. Variables such as sex and age were dichotomized when analyzing the $\mathrm{F}$ concentration in the toenails. For the TFI grade, its highest score was assigned to each child. These variables were compared using the Wilcoxon test (Mann-Whitney) at a significance level of $5 \%$.

\section{Result}

3.1. Changes in the DF Frequency according to the Birth Cohort. We included 274 children aged 8-18 years. We found a higher DF prevalence in 2018 (96.6\%) than in 2015 (85.1\%), but this difference was not significant $(P>0.05)$. The DF frequencies from 2015 to 2018 are shown in Table 1.

During the 2018 evaluation, we identified a higher DF frequency (RP 1.17; 95\% CI 0.89-1.55), compared to the 2015 evaluation (SGPV $=0.21)$. However, this difference cannot be explained by an increase in the DF incidence according to birth cohorts (Table 2).

\subsection{Fluoride Concentration in Biological and Environmental} Samples. We analyzed the F concentration in the toenails of 37 children. The mean age was $12.29 \pm 2.63$ years, and $54.0 \%$ was males. The mean $\mathrm{F}$ concentration in toenails was $2.48 \pm 2.29 \mu \mathrm{g} \mathrm{F} / \mathrm{g}(\mathrm{F} \mathrm{ppm})$, with a range value of $0.03-8.68 \mu \mathrm{g}$ $\mathrm{F} / \mathrm{g}$ (F ppm). 37.8\% of children presented values $\geq 2 \mu \mathrm{g} \mathrm{F} / \mathrm{g}$ (F ppm) [23] in the toenails. Table 3 shows the F concentration by sex, age, and TFI grade.

When comparing the $\mathrm{F}$ concentration in toenails according to age, gender, and TFI grade, we found no significant differences in the age and gender distribution, although the $\mathrm{F}$ mean concentration in children aged 7-12 years $(1.67 \pm 1.69 \mu \mathrm{g} \mathrm{F} / \mathrm{g})$ was lower than in children aged 13-18 years $(3.09 \pm 2.52 \mu \mathrm{g} \mathrm{F} / \mathrm{g})(P=0.06)$. The toenails of children with $\mathrm{TFI} \leq 3(n=23)$ presented a significantly higher F mean concentration $(3.17 \pm 2.40 \mu \mathrm{g} \mathrm{F} / \mathrm{g})$ compared to children with $\mathrm{TFI} \geq 4 \quad(n=14 ; \quad 1.33 \pm 1.56 \mu \mathrm{g} \quad \mathrm{F} / \mathrm{g})$ $(P=0.015)$.

Table 4 shows the $\mathrm{F}$ concentration in the soil, coal, and food samples. The mean $\mathrm{F}$ concentration was found to be very low $(0.12 \pm 0.146 \mu \mathrm{g} \mathrm{F} / \mathrm{g})$. The samples collected from the central part showed a slightly higher $\mathrm{F}$ concentration than those collected from the peripheral area, although the difference was not statistically significant. The mean $\mathrm{F}$ concentration found in the snacks (11 snacks-one sweetsoda) and one food-seasoning product was $0.5 \pm 0.55 \mu \mathrm{g} \mathrm{F} / \mathrm{g}$ ( $\mathrm{F}$ ppm F). A higher $\mathrm{F}$ concentration was found in salty snacks (Almuercito and Crakeñas cookies). Food seasoning showed the highest F concentration (6.7 $\mu \mathrm{g} \mathrm{F/g;} \mathrm{F} \mathrm{ppm).}$

\section{Discussion}

According to the birth cohort, the change in incidence cannot explain the increase in the DF frequency in El Cedro between 2015 and 2018. Although DF seems less frequent in older children (born 2000-2002), the magnitude is generalized. Although not significant, the difference in gender distribution may suggest a different risk exposure between 
TABLE 1: Distribution of the analyzed variables in the study children, 2015 and 2018.

\begin{tabular}{lccc}
\hline Variable & Cases & $n$ & $\%$ \\
\hline Examination year & & & \\
2015 & 80 & 94 & 85.1 \\
2018 & 177 & 180 & 96.6 \\
\hline Birth of cohort & & & \\
$2000-2002$ & 8 & 9 & 88.8 \\
$2003-2005$ & 116 & 121 & 95.8 \\
$2006-2008$ & 103 & 114 & 90.3 \\
$2009-2011$ & 30 & 30 & 100 \\
\hline Age (years) & & & \\
$8-9$ & 57 & 67 & 85 \\
$10-12$ & 129 & 134 & 96.2 \\
$13-15$ & 63 & 64 & 98.4 \\
$16-18$ & 8 & 9 & 88.8 \\
\hline
\end{tabular}

TABLE 2: Examination year and cohort analysis of the DF presence in the study children, 2015 and 2018.

\begin{tabular}{lcccc}
\hline & Ratio & $95 \%$ CI & $P$ value & SGPV $^{*}$ \\
\hline $\begin{array}{l}\text { Examination year } \\
\quad 2015\end{array}$ & 1.00 & & & \\
$\quad 2018$ & 1.17 & $0.89,1.55$ & 0.261 & 0.21 \\
Birth cohort & & & & \\
$\quad 2000-2002$ & 0.89 & $0.41,1.94$ & 0.767 & 0.574 \\
$2003-2005$ & 1.03 & $0.68,1.57$ & 0.889 & 0.461 \\
$2006-2008$ & 0.95 & $0.63,1.44$ & 0.804 & 0.559 \\
$2009-2011$ & 1.00 & & & \\
\hline
\end{tabular}

*Second-generation $P$ values.

TABLE 3: Fluoride concentration in the toenails by gender, age, and TFI score of the study children, 2018.

\begin{tabular}{lccc}
\hline Variable & $n(\%)$ & $\mu \mathrm{g} \mathrm{F} / \mathrm{g}^{*}$ & $P$ values \\
\hline Gender & & & \\
$\quad$ Male & $20(54.0)$ & $2.51 \pm 2.23$ & 0.989 \\
$\quad$ Female & $17(46.0)$ & $2.44 \pm 2.25$ & \\
Age (years) & & & \\
$\quad 8-12$ & $16(43.3)$ & $1.67 \pm 1.69$ & 0.060 \\
13-18 & $21(56.7)$ & $3.09 \pm 2.52$ & \\
TFI & & & \\
TF $\leq 3$ & $23(62.2)$ & $3.17 \pm 2.40$ & 0.015 \\
TF $\geq 4$ & $14(37.8)$ & $1.33 \pm 1.56$ & \\
\hline
\end{tabular}

${ }^{*}$ Mean (SD) $F=\mu \mathrm{g} \mathrm{F/g} \mathrm{(two} \mathrm{measurements).}$

males and females. Exposure time relates to the increase in the DF incidence among the birth cohorts.

As occurred in the 2006-2008 birth cohorts, which showed DF frequencies of 73.0\% (2015) and 98.7\% (2018), the variation between the birth cohorts suggests the presence of different associated factors according to the period. Older children (2000-2002) showed the lowest DF frequency in 2018 (88.8\%), which might indicate that some mild lesions may become clinically invisible over time, due to wear, leading to lower frequencies [24]. The age at which the clinical examination is performed is crucial to detect the disease clinically [5].
TABLE 4: Fluoride concentration in soil, coal, snacks, and food seasoning samples, 2018.

\begin{tabular}{lc}
\hline Sample & $\mu \mathrm{g} \mathrm{F} / \mathrm{g}$ \\
Soil central part & 0.30 \\
Coal ash central part & 0.20 \\
Soil peripheral part & 0.01 \\
Coal ash peripheral part & 0.00 \\
\hline Snacks & \\
Jell-pep strawberry milk & 0.10 \\
Candy punch & 0.10 \\
Colored miniatures & 0.10 \\
Sweet soda* & 0.20 \\
Milo cookies & 0.30 \\
Bubbaloo gum-strawberry-grape & 0.30 \\
Festival strawberry cookies & 0.40 \\
Bubbaloo gum-mango & 0.40 \\
Milk cookies & 0.50 \\
Mint candy & 0.60 \\
Almuercito & $\mathbf{1 . 0 0}$ \\
Crakeñas cookies & $\mathbf{2 . 0 0}$ \\
\hline Food seasoning & $\mathbf{6 . 7 0}$ \\
\hline
\end{tabular}

${ }^{*} \mu \mathrm{g} \mathrm{F} / \mathrm{ml}$.

As a secondary analysis, we explored $\mathrm{F}$ exposure in a series of DF cases. Nails are a noninvasive, readily available biomarker of chronic, subchronic, and acute F exposure. The $\mathrm{F}$ concentration found in the toenails confirms its value in measuring a community's chronic $\mathrm{F}[23,25]$. The exposure time reflects the increase in the DF incidence in the birth cohorts and coincides with the F concentration found in the study population's toenails. However, the sample size and lack of follow-up of the cohorts are considerable limitations of our study. And also, this study design cannot demonstrate a temporal connection between the $\mathrm{F}$ toenail concentration and the DF onset; however, it aligns with the high DF prevalence $(96.6 \%)$ found in this population. The $\mathrm{F}$ concentration shows the $\mathrm{F}$ intake level over a long period, which can be useful for DF risk assessment $[7,14,26]$. However, the age group of the studied cases is outside the window of susceptibility, and therefore, age is crucial when predicting or assessing the risk for DF.

Despite being a small sample, the results show a higher DF prevalence than another cohort study in a Mexican population with different exposures according to the domestic salt fluoridation program [13]. Due to the lack of specific incidence studies in Colombian populations, it is challenging to compare our findings with others from similar studies. The DF prevalence found in our study is higher than those found in other populations with drinking water fluoridation, such as the USA. In the US national surveys 1986-1987, 1999-2004, and 2011-2012, the DF prevalence has increased from $22 \%$ to $41 \%$ and to $65 \%$, respectively [15]. In Colombia, the reported DF prevalence is $11.5 \%$ (1998) and 62.1\% (2014-2015) [27].

The F concentration found in the studied cases' toenails coincides with that found in similar studies, i.e., toenail samples, age group, and the number of subjects, conducted in other geographic areas [20]. Elekdag-Turk et al. [25] found a mean $F$ concentration of $2.34 \pm 0.26 \mathrm{mg} / \mathrm{kg}$ in 
endemic regions and a mean of $0.98 \pm 0.08 \mathrm{mg} / \mathrm{kg}$ in nonendemic regions. Buzalaf et al. [20] and Amaral et al. [28] reported $\mathrm{F}$ concentrations of $1.49-2.80 \mathrm{mg} / \mathrm{kg}$ and 2.15 (0.39)-2.64 (0.41) $\mu \mathrm{g} \mathrm{F/g}$, respectively.

Our findings differ from other studies that used toenail samples. Buzalaf et al. [23] found a higher mean $\mathrm{F}$ concentration (4.22 (2.45) $\mu \mathrm{g} \mathrm{F/g).} \mathrm{Similarly,} \mathrm{in} \mathrm{regions} \mathrm{with} \mathrm{low}$ $\mathrm{F}$ in water, Idowu et al. [26] found $\mathrm{F}$ concentrations of 3.237 (2.636) and 3.378 (2.197) $\mu \mathrm{g} \mathrm{F/g}$ in fingernails and toenails, respectively. Also, the $\mathrm{F}$ concentration found in our study population is very low compared to areas with higher $\mathrm{F}$ in water, where F concentrations in nails of 10.420 (3.761) and 10.371(3.907) $\mu \mathrm{g} \mathrm{F/g} \mathrm{have} \mathrm{been} \mathrm{reported} \mathrm{[26].}$

Although some studies have reported higher $\mathrm{F}$ concentrations in fingernails than in toenails, it is currently recommended to use toenail samples, especially from the first toe, because it is fast growing and provides enough sample for the analysis. Some reports have shown that toenails are less exposed to external contamination than fingernails $[7,20,25,28]$. However, this can vary depending on the lifestyle of the rural populations.

When correlating the $\mathrm{F}$ concentration in toenails with age and DF severity according to the TFI [18], we found a higher concentration in the group aged 13-18 years, which may indicate a higher exposure over time [5], and also, it could indicate differences in the $\mathrm{F}$ absorption after tooth development. In contrast to other studies that showed that $\mathrm{F}$ concentration in nails increases with the DF severity [14, 23], we found a higher mean $\mathrm{F}$ concentration in children and adolescents with $\mathrm{TFI} \leq 3$. This divergence may indicate an altered $\mathrm{F}$ absorption in the study population, possibly due to genetics variations, epigenetic factors, malnutrition, diet composition in terms of protein, carbohydrates and fat, and intake of micronutrients such as calcium $[1,14,29,30]$.

Although El Cedro is considered an endemic region, its primary source of $\mathrm{F}$ exposure is unclear. The analyzed samples showed significant $\mathrm{F}$ concentration variability, with salty snacks and food seasoning presenting the highest concentrations. These findings concur with those from other studies, in which there is no direct correlation between the various analyzed sources, F concentration, and DF severity in endemic regions $[16,26,31]$. In Colombia, F concentration in salt has also shown a high variability and sometimes may exceed the maximum permitted level $[16,32]$. Each sample was measured twice for fluoride analysis, and the duplicate samples analysis has been used in different methods $[33,34]$. The F concentration found in this study in snacks and food-seasoning is similar to other F concentrations reported by Zohouri and Rugg-Gunn, for cereals $(0.2-03 \mu \mathrm{g} \mathrm{F} / \mathrm{g})$, mixtures of spice $(2.41 \mu \mathrm{g} \mathrm{F} / \mathrm{g})$, and chilli powder $(1.82 \mu \mathrm{g} \mathrm{F} / \mathrm{g})$ [33]. The difference in fluoride content that may appear in different snacks and food-seasoning lots is worthless, considering that the major source of fluoride on Earth provides from soil (rocks) and thereafter on salt. Assuming that package is manufactured on the same place with the same raw material, variations in parts per million (ppm) are despicable. Although the soil and coal samples were taken from only two places and thus not represent a probabilistic sample from various geographical areas, their low $\mathrm{F}$ concentration indicates its presence in the community environment.
Our findings regarding $\mathrm{F}$ concentration reflect a simple exploratory analyze. However, the lack of research on nails as an F biomarker and analysis of different elements in communities with salt fluoridation makes this study contribute to the knowledge of nails as a biomarker of $\mathrm{F}$ exposure and the DF frequency in low altitude, warm-humid climate endemic regions. There is a need for studies with a similar approach involving larger samples and considering DF window of susceptibility, i.e., 3 months to 8 years old $[5,20]$. Future studies conducted in this region should also consider other factors such as the increase in mining exploitation and access to dental services (last decade), diet, and salt intake, in order to contribute to the development of social and health policies.

The recommendations for $\mathrm{F}$ use should be based on the evidence of the risks and benefits for each population [11]. Actions such as those implemented in recent years in the USA and Malaysia, where F concentration in water was lowered to $0.7 \mathrm{mg} / \mathrm{L}$ [15] and $0.5-0.7 \mathrm{ppm}$ [35], respectively, can be adopted by other countries with fluoridated salt and endemic regions with fluorosis, such as Colombia. The study of $\mathrm{DF}$ in endemic regions requires a more in-depth analysis to understand its etiological, epidemiological, and biological contexts. DF prevalence is increasing in this population as in the world; DF and the F concentrations are related, but its clinical manifestation and variations in the populations are multifactorial.

\section{Conclusion}

In this population with a high DF frequency according to the birth cohort and evaluated period, the study of soil, coal, and food samples indicates a continued $\mathrm{F}$ exposure. F concentration found in the toenails shows a moderate $\mathrm{F}$ exposure; nearly a third of the children and adolescents exceeded the adopted threshold of $2 \mu \mathrm{g} \mathrm{F} / \mathrm{g}$. It is important to monitor and explore changes in exposure in highly affected population.

\section{Data Availability}

The data used to support the findings of this study are available from the corresponding author upon request.

\section{Conflicts of Interest}

The authors declare that they have no conflicts of interest.

\section{Authors' Contributions}

All authors contributed to the manuscript preparation. AS and FJ designed the study, collected and analyzed the data, and carried out the first draft of the article. MR, DFRG, TSC, MARB, and LSP analyzed the data and wrote, reviewed, and edited the article.

\section{Acknowledgments}

The authors would like to thank the participants and CES University for providing access to the community and the financial support (INV032017008). 


\section{References}

[1] P. DenBesten and W. Li, "Chronic fluoride toxicity: dental fluorosis," Fluoride and the Oral Environment, vol. 22, pp. 81-96, 2011.

[2] A. I. Ismail and H. Hasson, "Fluoride supplements, dental caries and fluorosis," The Journal of the American Dental Association, vol. 139, no. 11, pp. 1457-1468, 2008.

[3] S. M. Levy, S. L. Hillis, J. J. Warren et al., "Primary tooth fluorosis and fluoride intake during the first year of life," Community Dentistry and Oral Epidemiology, vol. 30, no. 4, pp. 286-295, 2002.

[4] T. Aoba and O. Fejerskov, "Dental fluorosis: chemistry and biology," Critical Reviews in Oral Biology \& Medicine, vol. 13, no. 2, pp. 155-170, 2002.

[5] P. Bhagavatula, S. M. Levy, B. Broffitt, K. Weber-Gasparoni, and J. J. Warren, "Timing of fluoride intake and dental fluorosis on late-erupting permanent teeth," Community Dentistry and Oral Epidemiology, vol. 44, no. 1, pp. 32-45, 2016.

[6] L. Hong, S. M. Levy, B. Broffitt et al., "Timing of fluoride intake in relation to development of fluorosis on maxillary central incisors," Community Dentistry and Oral Epidemiology, vol. 34, no. 4, pp. 299-309, 2006.

[7] G. M. Whitford, F. C. Sampaio, P. Arneberg, and F. R. Von der Fehr, "Fingernail fluoride: a method for monitoring fluoride exposure," Caries Research, vol. 33, no. 6, pp. 462-467, 1999.

[8] L. G. Do, A. J. Spencer, and D. H. Ha, "Association between dental caries and fluorosis among South Australian children," Caries Research, vol. 43, no. 5, pp. 366-373, 2009.

[9] F. V. Zohoori, P. J. Moynihan, N. Omid, L. Abuhaloob, and A. Maguire, "Impact of water fluoride concentration on the fluoride content of infant foods and drinks requiring preparation with liquids before feeding," Community Dentistry and Oral Epidemiology, vol. 40, no. 5, pp. 432-440, 2012.

[10] Y. Li, W. Wang, L. Yang, and H. Li, "Environmental epidemic characteristics of coal burning endemic fluorosis and the safety threshold of coal fluoride in China," Fluoride, vol. 36, no. 2, pp. 106-112, 2003.

[11] L. G. Do, D. H. Ha, and A. J. Spencer, "Natural history and long-term impact of dental fluorosis: a prospective cohort study," Medical Journal of Australia, vol. 204, no. 1, p. 25, 2016.

[12] I. A. Pretty, N. Boothman, J. Morris et al., "Prevalence and severity of dental fluorosis in four English cities," Community Dental Health, vol. 33, no. 4, pp. 292-296, 2016.

[13] A. J. Casanova-Rosado, C. E. Medina-Solís, J. F. CasanovaRosado et al., "Prevalencia de fluorosis dental en ocho cohortes de Mexicanos nacidos durante la instauración del programa Nacional de Fluoruración de la Sal Doméstica," Gaceta Médica de México, vol. 149, no. 1, pp. 27-35, 2013.

[14] M. A. R. Buzalaf, "Review of fluoride intake and appropriateness of current guidelines," Advances in Dental Research, vol. 29, no. 2, pp. 157-166, 2018.

[15] C. Neurath, H. Limeback, B. Osmunson, M. Connett, V. Kanter, and C. R. Wells, "Dental fluorosis trends in US oral health surveys: 1986 to 2012," JDR Clinical \& Translational Research, vol. 4, no. 4, pp. 298-308, 2019.

[16] M. Restrepo, F. Jeremias, and L. Santos-Pinto, Estudo epidemiologico de defeitos de esmalte e cárie dentária e o impacto na qualidade de vida en criancas expostas a altos níveis de flúor, Ph.D. thesis, Araraquara School of Dentistry, Sáo Paulo, Brazil, 2016, https://repositorio.unesp.br/handle/11449/147065.
[17] World Health organization, Ed., Oral Health Surveys: Basic Methods, WHO, Geneva, Switzerland, 5th edition, 2013.

[18] A. Thylstrup and O. Fejerskov, "Clinical appearance of dental fluorosis in permanent teeth in relation to histologic changes," Community Dentistry and Oral Epidemiology, vol. 6, no. 6, pp. 315-328, 1978.

[19] W. K. Seow, "Clinical diagnosis of enamel defects: pitfalls and practical guidelines," International Dental Journal, vol. 47, no. 3, pp. 173-182, 1997.

[20] M. A. R. Buzalaf, F. V. Vilhena, F. G. Iano et al., "The effect of different fluoride concentrations and $\mathrm{pH}$ of dentifrices on plaque and nail fluoride levels in young children," Caries Research, vol. 43, no. 2, pp. 142-146, 2009.

[21] D. R. Taves, "Separation of fluoride by rapid diffusion using hexamethyldisiloxane," Talanta, vol. 15, no. 9, pp. 969-974, 1968.

[22] J. D. Blume, R. A. Greevy, V. F. Welty, J. R. Smith, and W. D. Dupont, "An introduction to second-generation $P$ values," The American Statistician, vol. 73, no. 1, pp. 157-167, 2019.

[23] M. A. R. Buzalaf, C. S. Massaro, M. H. C. Rodrigues et al., "Validation of fingernail fluoride concentration as a predictor of risk for dental fluorosis," Caries Research, vol. 46, no. 4, pp. 394-400, 2012.

[24] A. M. Curtis, S. M. Levy, J. E. Cavanaugh, J. J. Warren, J. L. Kolker, and K. Weber-Gasparoni, "Decline in dental fluorosis severity during adolescence: a cohort study," Journal of Dental Research, vol. 99, pp. 1-7, 2020.

[25] S. Elekdag-Turk, M. Almuzian, T. Turk et al., "Big toenail and hair samples as biomarkers for fluoride exposure-a pilot study," BMC Oral Health, vol. 19, pp. 82-87, 2019.

[26] O. S. Idowu, R. M. Duckworth, R. A. Valentine, and F. V. Zohoori, "Biomarkers for the assessment of fluoride exposure in children," Caries Research, vol. 54, no. 2, pp. 134-143, 2020.

[27] República de Colombia, Ministerio de Salud y protección Social, IV Estudio Nacional de Salud Bucal: Situación de salud bucal, ENSAB IV, Bogotá, Colombia, 2015.

[28] J. G. Amaral, I. R. Freire, E. F. R. Valle-Neto, R. F. Cunha, C. C. R. Martinhon, and A. C. B. Delbem, "Longitudinal evaluation of fluoride levels in nails of 18-30-month-old children that were using toothpastes with 500 and $1100 \mu \mathrm{g} \mathrm{F} /$ g," Community Dentistry and Oral Epidemiology, vol. 42, no. 5, pp. 412-419, 2014.

[29] S. Charone, E. C. Küchler, A. d. L. Leite et al., "Analysis of polymorphisms in genes differentially expressed in the enamel of mice with different genetic susceptibilities to dental fluorosis," Caries Research, vol. 53, no. 2, pp. 228-233, 2019.

[30] O. Ibiyemi, F. V. Zohoori, R. A. Valentine, and A. Maguire, "Fluoride intake and urinary fluoride excretion in 4-and 8year-old children living in urban and rural areas of Southwest Nigeria," Community Dentistry and Oral Epidemiology, vol. 46, no. 5, pp. 482-491, 2018.

[31] S. Martignon, M. O. Opazo-Gutierrez, M. Velasquez-Riaño et al., "Geochemical characterization of fluoride in water; table salt, active sediment, rock and soil samples, and its possible relationship with the prevalence of enamel fluorosis in children in four municipalities of the department of Huila (Colombia)," Environmental and Monitoring Assessment, vol. 189, no. 6, p. 264, 2017.

[32] A. M. Franco, A. Saldarriaga, M. C. González, S. Martignon et al., "Concentración de flúor en la sal de cocina en cuatro ciudades colombianas," CES Odontologia, vol. 16, no. 1, pp. 21-26, 2003. 
[33] F. V. Zohouri and A. J. Rugg-Gunn, "Fluoride concentration in foods from Iran," International Journal of Food Sciences and Nutrition, vol. 50, no. 4, pp. 265-274, 1999.

[34] H. G. Mikkonen, R. de Graaff, A. T. Mikkonen et al., "Environmental and anthropogenic influences on ambient background concentrations of fluoride in soil," Environmental Pollution, vol. 242, pp. 1838-1849, 2018.

[35] N. A. Mohd Nor, B. L. Chadwick, D. J. J. Farnell, and I. G. Chestnutt, "The impact of a reduction in fluoride concentration in the Malaysian water supply on the prevalence of fluorosis and dental caries," Community Dentistry and Oral Epidemiology, vol. 46, no. 5, pp. 492-499, 2018. 